\title{
DEGRADAÇÃO DO CORANTE ALARANJADO DE METILA VIA OXIDAÇÃO AVANÇADA CATALISADA POR TIO2 UTILIZADA PARA TRATAMENTO DE EFLUENTE
}

\author{
R. F. S. $\operatorname{COSTA}^{1}$, C. M. e CASTRO ${ }^{1}$ e F. L. das NAVES ${ }^{1}$ \\ ${ }^{1}$ Universidade Federal de São João del Rei, Campus Alto Paraopeba, \\ Departamento de Engenharia Química e Estatística. \\ E-mail para contato: rai.costa09@gmail.com
}

\begin{abstract}
RESUMO - A cada dia há uma maior preocupação com o meio ambiente, o que nos leva a estudar novas formas de preservá-lo, uma das formas é por meios de pesquisas relacionadas com novos tratamentos para os efluentes, estes que são um grande problema industrial. Dentre as alternativas que se destacam temos os processos oxidativos avançados, estes são métodos eficientes com baixo custo operacional e de fácil implementação na indústria, que englobam reações geradoras de radicais livres responsáveis pela degradação do contaminante. $\mathrm{O}$ objetivo desse trabalho foi avaliar a degradação do corante alaranjado de metila via oxidação avançada catalisado através de $\mathrm{TiO} 2$. Foram analisados a vazão, $\mathrm{pH}$ e potência do ozonizador visando avaliar se esses fatores contribuem para maior degradação do corante. A degradação do alaranjado de metila mostrou-se mais eficiente, atingindo os maiores valores de demanda química de oxigênio (DQO) em $\mathrm{pH}$, potência e vazão a $6 ; 70 \% \mathrm{~W}$ e $4,5 \mathrm{l} / \mathrm{min}$.
\end{abstract}

\section{INTRODUÇÃO}

Os corantes são substâncias comumente usadas em atividades laboratoriais e em vários ramos industriais como têxteis, de alimentos, cosméticos e celulose. O resíduo desse material descartado de forma indevida gera danos ao meio ambiente porque a coloração interfere nos processos fotossintéticos e contaminam lagos, rios e mananciais (Carvalho et al, 2009). Pelo fato de serem substancias quimicamente estáveis, a remoção dos corantes é ineficiente em processos biodegradáveis, de precipitação ou coagulação (Aguiar, 2012).

Dentre as novas técnicas desenvolvidas para a descoloração do efluente como a adsorção, precipitação, biodegradação e eletroquímica (Guaratini e Zanoni, 2002), os processos oxidativos avançados, conhecidos como Poas, ganharam destaque por serem um método barato, versátil e de fácil implementação no processo industrial. Em contrapartida, esse processo tem grande tempo de retenção e formação de subprodutos (Araujo et al, 2016). 
Os Poas são procedimentos físico-químicos onde contaminantes orgânicos em dióxido de carbono, água e ânions inorgânicos são transformados em radicais livres, principalmente o radical hidroxil, que possuem alto poder oxidante e não seletividade. Esses radicais degradam vários poluentes gerando a mineralização total dos componentes e a oxidação total de substâncias inorgânicas (Fioreze et al, 2014).

Dentre os vários reagentes responsáveis pelos processos oxidativos avançados como radiação UV e peroxido de hidrogênio, o ozônio é um dos mais promissores oxidantes na remoção de corantes, pois ataca a ligação dupla presente dos grupos cromóforos (Polat et al, 2015). Possui vantagens como o alto potencial de oxidação, o que causa a maior eficiência da decomposição e é pouco sensível a alterações de temperatura (Rodrigues, 2004).

$\mathrm{O}$ uso do ozônio é comumente associado com o TiO2, por ser um metal semicondutor eficiente na degradação de substâncias orgânicas e de baixo custo (Schneider et al, 2014). Nesse contexto, o objetivo desse trabalho foi avaliar a eficiência dos processos oxidativos avançados por ozonização para a degradação do corante alaranjado de metila.

\section{METODOLOGIA}

\subsection{Sistema de tratamento}

Os experimentos foram realizados em um sistema de ozonização contendo um gerador de ozônio, um reator de $0,5 \mathrm{~L}$ e um pHmetro. Esse aparato experimental foi acoplado em um sistema de exaustão no interior de uma capela. A vazão do ar que entra no equipamento foi controlada por um fluxometro calibrado para ar, com uma escala de 0 a $15 \mathrm{~L} / \mathrm{min}$. $\mathrm{O}$ controle de $\mathrm{pH}$ foi realizado adicionando solução de ácido sulfúrico e hidróxido de sódio, ambos com concentração $0,1 \mathrm{~mol} / \mathrm{L}$. O gerador de ozônio foi controlado através de um potenciômetro com escala de 0 a 200W. Através do programa Minitab®, realizou um planejando experimental. Foram realizados 10 experimentos, variando os valores de ph, vazão e potência do ozonizador. A variável de resposta a ser analisada foi a demanda química de oxigênio (DQO). O dióxido de titânio foi impregnado em esferas de zeolitas através do método Dip Coating.

\subsection{Coleta e análise de dados}

Amostras de corante com concentração de $3,05 \times 10^{-4} \mathrm{~mol} / \mathrm{L}$ foram inseridas no reator juntamente com as esferas de zeolita. O tempo de execução foi de uma hora para cada

experimento e a cada procedimento, foram retiradas amostras antes e depois do procedimento. Para obter os valores de DQO, utilizou-se procedimentos propostos pelo

STANDARD METHODS 1998 5220D, que fornece valores de DQO a partir da oxidação em meio ácido. $O$ cálculo é realizado através da equação 1 :

$$
\% \text { Redução de } D Q O=\frac{D Q o_{A m, b r u t a}-D Q o_{A m, t r a t a d a}}{D Q o_{A m, \text { tratada }}}
$$




\section{RESULTADOS E DISCUSSÃO}

Como parte essencial da ação do ozônio, observamos primeiramente a mudança de cor. Isso ocorre porque o ozônio ataca a dupla ligação do grupo azo presente no corante que está relacionada a coloração. A baixa dosagem de ozônio é capaz de romper essa ligação que reage através de ataque eletrolítico. A tabela 1 , apresenta os valores de $\mathrm{pH}$, vazão e potência utilizados em cada experimento com os valores de DQO obtidos. Nota-se que em valores medianos de $\mathrm{pH}$, vazão e potência foram obtidos a maior porcentagem de redução de DQO.

Tabela 1 - Valores de pH, vazão e potência do ozonizador e as porcentagens de redução de DQO obtidos

\begin{tabular}{|c|c|c|c|c|}
\hline Experimento & $\mathbf{p H}$ & $\begin{array}{c}\text { Vazão } \\
(\mathbf{L} / \mathbf{m i n})\end{array}$ & $\begin{array}{c}\text { Potência } \\
(\boldsymbol{\%})\end{array}$ & $\begin{array}{c}\text { \% redução } \\
\text { DQO }\end{array}$ \\
\hline 1 & 3 & 3 & 50 & 38,10 \\
\hline 2 & 9 & 3 & 50 & 44,32 \\
\hline 3 & 3 & 6 & 50 & 37,06 \\
\hline 4 & 9 & 6 & 50 & 41,52 \\
\hline 5 & 3 & 3 & 90 & 37,22 \\
\hline 6 & 9 & 3 & 90 & 20,99 \\
\hline 7 & 3 & 6 & 90 & 39,89 \\
\hline 8 & 9 & 6 & 90 & 24,20 \\
\hline 9 & 0,9 & 4,5 & 70 & 45,32 \\
\hline 10 & 11, & 4,5 & 70 & 42,63 \\
\hline 11 & 6 & 1,98 & 70 & 31,26 \\
\hline 12 & 6 & 7,02 & 70 & 27,40 \\
\hline 13 & 6 & 4,5 & 36,36 & 41,55 \\
\hline 14 & 6 & 4,5 & 103,64 & 23,44 \\
\hline 15 & 6 & 4,5 & 70 & 49,07 \\
\hline 16 & 6 & 4,5 & 70 & 51,12 \\
\hline 17 & 6 & 4,5 & 70 & 45,99 \\
\hline 18 & 6 & 4,5 & 70 & 50,02 \\
\hline 19 & 6 & 4,5 & 70 & 53,18 \\
\hline 20 & 6 & 4,5 & 70 & 48,74 \\
\hline
\end{tabular}

Para Von Guntem (2003), o pH é o fator que influencia o início da degradação do corante, sendo que quanto mais $\mathrm{OH}^{-}$existir no meio, mais rápido será a decomposição do ozônio, contribuindo para um rápido ataque no grupo azo. Sabe-se que em pH ácidos, a ozonização ocorre via ozônio molecular e pH básico, há a degradação do ozônio no meio (Castro, 2016).

Já a potência do ozonizador pode ser entendida como a energia depositada no sistema onde maior energia inserida no sistema, maior campo elétrico. Desse modo, os elétrons, que são os principais agentes formadores de espécies quimicamente ativas são gerados em maior 


\section{Congresso Brasileiro de Engenharia Química em Iniciação Científica UFSCar - São Carlos - SP 16 a 19 de Julho de 2017}

quantidade o que aumenta a probabilidade de mais reações por impacto (Cadorni, 2009). Todavia, há um limite no aumento da potência, pois, a produção em excesso de NOx irá também competir com o consumo de átomos de oxigênio, provocando a redução da formação de radicais hidroxila e a redução da quantidade de ozônio disponível no sistema (Tang et al, 2009).

A vazão está correlacionada com o tamanho de bolha no reator, relacionado diretamente com a transferência de massa entre a fase gasosa e liquida. Quanto menor as bolhas, melhor a transferência de fase e maior será a quantidade de ozônio no meio (Mahmoud,2006).

Para determinar o comportamento da degradação, utilizou a metodologia de superfície que é adequada para esse experimento, já que a variável de resposta depende de vários fatores. Pelo programa Minitab® realizou a regressão da superfície de resposta com seus coeficientes. Para comprovar sua confiabilidade, analisou o coeficiente de determinação de ajuste da equação $\left(\mathrm{R}^{2}\right)$ que resultou no valor de $94,45 \%$, valor muito próximo ao $100 \%$ que é considerado o valor ótimo. Logo, determinou que o comportamento é de acordo com equação 2, onde $\mathrm{x}_{1}, \mathrm{x}_{2}$ e $\mathrm{x}_{3}$ corresponde a $\mathrm{pH}$, vazão e potência do ozonizador (Montgomery, 2006).

$$
\begin{gathered}
D Q O=49,6522-1,8867 x_{1}-0,3263 x_{2}-5,0642 x_{3}-1,80214 x_{1}^{2}-6,9806 x_{2}^{2}-5,8619 x_{3}^{2} \\
-0,1529 x_{1} x_{2}-5,3250 x_{1} x_{2}-1,2150 x_{2} x_{3}
\end{gathered}
$$

\section{CONCLUSÕES}

A ozonização mostrou ser um processo eficaz para o tratamento de efluentes contendo corantes como o alaranjado de metila. Foi possível com o nosso estudo degradar o efluente de forma rápida e com baixo custo. Sendo esse um produto que pode ser indicado para tratar efluentes que possuam o corante estudado.

\section{REFERENCIAS}

AGUIAR, J. E. de. Remoção de corantes têxteis utilizando adsorventes nanoporosos. Dissertação de Mestrado. Programa de Pós-Graduação em Engenharia Química. Universidade Federal de Ceará. Fortaleza, 2012.

ARAUJO, K. S. DE; ANTONELLI, R.; GAYDECZKA, B.; GRANATO, A. C.; MALPASS, G. R. P.; Processos oxidativos avançados: uma revisão de fundamentos e aplicações no tratamento de águas residuais urbanas e efluentes industriais. Revista Ambiental Água. Volume 11, número 2. Abril/ Junho, 2016.

CADORIN, B. M. Degradação do corante alaranjado de metila por plasma frio de descarga corona. Departamento de Química. Universidade Federal de Santa Catarina. Florianopolis, 2009.

CARVAlHO, T. E. M. DE; FURGARO, D. A.; IZIDORO, J. DE C. Adsorção do corante reativo laranja 16 de soluções aquosa por zeólitas sintética. Revista Química Nova. Volume 33, Páginas 358 - 363. Dezembro, 2009.

CASTRO, F. D. Degradação do corante azo laranja reativo 16 por ozônio, identificação dos intermediários e metabolização em reator MBBR. Dissertação de mestrado. Programa de Pós-Graduação de Engenharia Química. Universidade Federal do Rio de Janeiro. Rio de Janeiro, 2016 


\section{Congresso Brasileiro de Engenharia \\ Química em Iniciação Científica \\ UFSCar - São Carlos - SP \\ 16 a 19 de Julho de 2017}

GUARATINI, C. C. I.; ZANONI, M. V. B. Corantes têxteis. Revista Química Nova, Volume 23, Issues 1, 71-78, 2000.

FIOREZE, M.; SANTOS, E. P. dos; SCHMACHTENBERG, N. Processos oxidativos avançados: fundamentos e aplicação ambiental. Revista Eletronica em Gestão, Educação e Tecnologia Ambiental - REGET. e-ISSN 22361170 - V. 18, n. 1, p. 79-91, 2014.

MAHMOUD, A. Avaliação de métodos emergentes visando aumentar a eficiência do ozônio na mineralização do azocorante Preto Remazol B. Dissertação de Mestrado. Programa de Pós Graduação de Química. Universidade de São Paulo. São Paulo, 2006

MONTGOMERY, D. C. Design and Analysis of Experiments. [s.1.] Hoboken: John Wiley \& Sons, 2006.

POLAT, D., BALCI, I., ÖZBELGE, T. A. Catalytic ozonation of an industrial textile wastewater in a heterogeneous continuous reactor. Department of Chemical Engineering, Middle East Technical University. Ankara, Turkey, 2015.

RODRIGUES, F.S.F. Aplicação da ozonização e do reativo de fenton como pré-tratamento de chorume com os objetivos de redução da toxicidade e do impacto no processo biológico. Dissertação de mestrado. Programa de Pós- Graduação em Engenharia Civil, Área de concentração: recursos hídricos. Universidade Federal do Rio de Janeiro. Rio de Janeiro 2004.

SCHNEIDER, M. V. et al. Degradação fotocatalítica de bentazona com TiO2. Engenharia Sanitária Ambiental. v.19 n.1. jan/mar 2014 | 61-66

TANG, Q. JIANG, W. ZHANG, Y. WEI, W. LIM, T. M. Degradation of Azo Dye Acid Red 88 by gas phase dielectric barrier discharges. Plasma Chem Plasma Process. 29:291305. 2009.

VON GUNTEN, U. Ozonation of drinking water: Part I. Oxidation kinetics and product formation. Water Research, v. 37, p. 1443-1467, 2003. 